\title{
Distribution of crabs along a habitat gradient on the Yellow Sea coast after Spartina alterniflora invasion
}

\author{
Pan Chen ${ }^{1,2}$, Yan Zhang ${ }^{1}$, Xiaojing Zhu ${ }^{1}$, Changhu Lu ${ }^{\text {Corresp. } 1}$ \\ ${ }^{1}$ College of Biology and the Environment, Nanjing Forestry University, Nanjing, Jiangsu, China \\ 2 College of Environment and Engineering, Anhui Normal University, Wuhu, Anhui, China \\ Corresponding Author: Changhu Lu \\ Email address: luchanghu@njfu.com.cn
}

The effects of Spartina alterniflora invasion on macrobenthos have long been of concern; however, there is currently no unified conclusion regarding these effects. Most studies on crabs focus on one species or limited habitat types, and assessments of the communitylevel effects of $S$. alterniflora invasion considering multiple species and habitat types have rarely been conducted. In this study, we sampled crabs along a habitat gradient from the shoreline to inland areas on the Yellow Sea coast, including the mudflat, S. alterniflora marsh, Suaeda salsa marsh and Phragmites australis marsh. A total of ten crab species were found among all habitats, with five species in the mudflat, six species in $S$.

alterniflora marsh, seven species in S. salsa marsh, and four species in $P$. australis marsh. The Shannon index values for the crab communities were similar between $S$. alterniflora marsh and S. salsa marsh, and these values were significantly higher than those for the mudflat and $P$. australis marsh. However, the total biomass of crabs was highest in the mudflat, and Metaplax longipes, Philyra pisum and Macrophthalmus dilatatus exclusively preferred the mudflat. The analysis of principal components and similarities showed that the crab community structure in $S$. alterniflora marsh was most similar to that in $S$. salsa marsh, while the crab community structure in the mudflat was most different from that in the other habitat types. Our results demonstrate that the distribution of crabs varies across a habitat gradient after $S$. alterniflora invasion and that the crab community in $S$. alterniflora marsh is slightly different from that associated with the local vegetation but shows a large difference from that in the mudflat. This study indicates that some crab species may have adapted to habitat containing alien $S$. alterniflora, while other crab species reject this new marsh type. The effects of the distribution of crabs after $S$. alterniflora invasion on the regional ecosystem need further study in the future. 


\section{Distribution of crabs along a habitat gradient on the Yellow}

3 Sea coast after Spartina alterniflora invasion

Pan Chen ${ }^{1,2}$, Yan Zhang ${ }^{1}$, Xiaojing Zhu ${ }^{1}$, Changhu $\mathrm{Lu}^{1}$

${ }^{1}$ College of Biology and the Environment, Nanjing Forestry University, Nanjing, Jiangsu, China

${ }^{2}$ College of Environment and Engineering, Anhui Normal University, Wuhu, Anhui, China 9

Corresponding Author:

Changhu $\mathrm{Lu}^{1}$

\section{Abstract}

The effects of Spartina alterniflora invasion on macrobenthos have long been of concern; however, there is currently no unified conclusion regarding these effects. Most studies on crabs focus on one species or limited habitat types, and assessments of the community-level effects of S. alterniflora invasion considering multiple species and habitat types have rarely been conducted. In this study, we sampled crabs along a habitat gradient from the shoreline to inland areas on the Yellow Sea coast, including the mudflat, S. alterniflora marsh, Suaeda salsa marsh and Phragmites australis marsh. A total of ten crab species were found among all habitats, with five species in the mudflat, six species in S. alterniflora marsh, seven species in S. salsa marsh, and four species in $P$. australis marsh. The Shannon index values for the crab communities were similar between $S$. alterniflora marsh and $S$. salsa marsh, and these values were significantly higher than those for the mudflat and P. australis marsh. However, the total biomass of crabs was highest in the mudflat, and Metaplax longipes, Philyra pisum and Macrophthalmus dilatatus exclusively preferred the mudflat. The analysis of principal components and similarities showed that the crab community structure in $S$. alterniflora marsh was most similar to that in $S$. salsa marsh, while the crab community structure in the mudflat was most different from that in the other habitat types. Our results demonstrate that the distribution of crabs varies across a habitat gradient after S. alterniflora invasion and that the crab community in S. alterniflora marsh is slightly different from that associated with the local vegetation but shows a large difference from that in the mudflat. This study indicates that some crab species may have adapted to habitat containing alien S. alterniflora, while other crab species reject this new marsh type. The effects of the distribution of crabs after $S$. alterniflora invasion on the regional ecosystem need further study in the future.

\section{Introduction}


40 Biological invasions often threaten the existence of native species and potentially destroy the 41 structure and function of ecosystems, which is one of the essential causes leading to the loss of 42 global biodiversity (Butchart et al. 2010; Genovesi et al. 2015). Exotic plants can strongly alter 43 the biotic and abiotic traits of local ecosystems (Sheehan \& Ellison 2014), affecting many taxa, 44 such as plants, insects, birds, and benthos (Li et al. 2009). Spartina alterniflora (Poaceae), which 45 is native to the Atlantic and Gulf coasts of North America, is one of the most notable plant 46 invaders, with strong fecundity and ecological adaptability (Nishijima et al. 2016). S. alterniflora

78 Materials \& Methods

79 Study site 
80 Field work was conducted in the core area of Yancheng National Nature Reserve $\left(32^{\circ} 59^{\prime} \mathrm{N}\right.$ to

$33^{\circ} 03^{\prime} \mathrm{N}, 120^{\circ} 47^{\prime} \mathrm{E}$ to $120^{\circ} 53^{\prime} \mathrm{E}$ ) in Jiangsu Province, China, from April to September in 2017.

The reserve is a typical intertidal wetland located along the Yellow Sea coast in eastern China (2 $\mathrm{m}$ to $4 \mathrm{~m}$ above sea level); it has high biodiversity and serves as an important stopover for a variety of migratory shorebirds (Melville et al. 2016). The annual average temperature is $14.1^{\circ} \mathrm{C}$, with the lowest monthly mean temperature of $0.8^{\circ} \mathrm{C}$ occurring in January and the highest monthly mean temperature of $27.0^{\circ} \mathrm{C}$ occurring in July. The average precipitation is $1068 \mathrm{~mm}$, with rain falling mostly in summer. The reserve was listed as a Ramsar wetland in 2002 and joined the Asia-Australasia bird migration protection network in 2003 (Jiang \& Ding 2011). Due to the occurrence of intense anthropogenic economic activity, many areas along the Yellow Sea coastline have lost their original natural features (Melville et al. 2016). Our study site was located in the core area of the reserve, with almost no human disturbance, retaining the rare natural landscape of the Yellow Sea tidal flat.

\section{Vegetation Distribution}

A satellite image of the study site was first obtained from Google Earth Pro (Google LLC, 2017), followed by a landscape-scale analysis of the vegetation types (Fig. 1). Then, several plant characteristics that may affect the distribution of crabs were assessed during the peak of the growing season. These characteristics were measured in 10 randomly positioned $1 \mathrm{~m}^{2}$ quadrats (1 $\mathrm{m} \times 1 \mathrm{~m}$ ) in each of three habitat types (P. australis, S. alterniflora and $S$. salsa), and the distance between each quadrat was not less than $20 \mathrm{~m}$. Within each quadrat, the number of culms was recorded, and 10 culms were randomly selected to measure the height using measuring tape. The number of culms per unit area represented the plant density.

\section{Crab Sampling}

To examine the distribution of crab communities in the tidal wetland, crabs were sampled from four marsh types (mudflat, S. alterniflora, S. salsa, P. australis). In our study area, the mean high tide level was approximately $4.68 \mathrm{~m}$, and the mean low tide level was approximately $1.09 \mathrm{~m}$. The sampled mudflat was approximately $1.5 \mathrm{~m}$ to $2 \mathrm{~m}$ above sea level and bare at low tide; the other three sampled habitats were approximately $3 \mathrm{~m}$ to $4 \mathrm{~m}$ above sea level and flooded at high tide. From April to September 2017, pitfall traps were used to catch crabs once a month according to methods described in other recent studies (Brusati \& Grosholz 2009; Cui et al. 2011). We did not collect crabs during the winter because the crabs were not active due to the low temperatures. Four quadrats $(20 \mathrm{~m} \times 20 \mathrm{~m})$ were established in each of the four habitat types, and each quadrat in each habitat type was located more than $20 \mathrm{~m}$ away from the edge of the habitat. Six pitfall traps were deployed in each quadrat by burying cylindrical plastic buckets $(20 \mathrm{~cm}$ in diameter, $30 \mathrm{~cm}$ deep) at the soil surface, and the distance between the buckets was not less than $10 \mathrm{~m}$. After one week, the crabs in each trap were checked, identified to species, and counted. According to feeding classification studies describing crab functional groups (Navarro et al. 2013; Zhang et al. 2017), the crabs were divided into three categories: carnivorous crabs, phytophagous crabs and omnivorous crabs. We did not obtain data in August because heavy rainfall destroyed the traps. Therefore, we only used the data from April, May, June, July, and 
120 September for the final analysis.

121 Data Analysis

122 The differences in the characteristics of plants, the number of species and biomass of crabs, and 123 the Shannon diversity index of the crab communities among the four habitat types were

124 examined using one-way ANOVA. The total biomass and Shannon diversity index values were 125 calculated using the data from the crabs in each quadrat. To meet the assumptions of ANOVA, 126 the numeric data were log or arcsine transformed prior to statistical analysis if necessary, and a 127 Tukey HSD test followed if a significant difference was found. A principal component analysis 128 (PCA) was performed to reduce the dimensions of the crab data to graphically analyze the 129 patterns of the crab community structure according to habitat type. Each community was plotted 130 as a point in space created by the first two PCA axes. Then, we tested for differences among 131 habitats using one-way analysis of similarities (ANOSIM) (Clarke \& Warrick, 1994) and used analysis of dissimilarity (SIMPER) to identify the species driving the dissimilarity among habitats (the relative contribution of individual species to the dissimilarity) (Clarke \& Warrick, 2001). Before the ANOSIM and SIMPER analyses, the data were square root transformed to give equal weight to rare taxa, and a Bray-Curtis similarity matrix was generated (Bray \& Curtis, 1957). We also showed the temporal and spatial changes in the biomass of different crab species with multiple bar charts to evaluate the stability of the abundance of the individual crab species. All statistical analyses and graphing procedures were performed using the software $\mathrm{R}$ (version 3.5.1, R Core Team, 2018) with the FactoMineR (used for the PCA), vegan (used for the ANOSIM and SIMPER) and ggplot2 packages (Wickham, 2016).

\section{Results}

\section{Plant characteristics}

144 In the different habitat types, there were significant differences in the plant height and stem density (Table 1). P. australis marsh had the greatest plant height $\left(F_{2,297}=805.4, p<0.001\right)$, and $S$. alterniflora marsh had the greatest population density $\left(F_{2,27}=102.4, p<0.001\right)$. The plant height and density in $S$. salsa marsh were significantly lower than those in the other two habitats.

\section{Composition of Crab Species}

150

A total of ten crab species were found among all habitats, with five species in the mudflat, six species in S. alterniflora marsh, seven species in S. salsa marsh, and four species in P. australis marsh. Most species belonged to the phytophagous group, while the carnivorous group was represented by one species, and the omnivorous group contained two species (Table 2). There were significant differences in the composition of the crab communities and the density of each crab species in the different habitat types (Table 2). The dominant species in the mudflat were Philyra pisum and Macrophthalmus dilatatus, but there were no obvious dominant species in the other three habitat types. $P$. pisum, M. dilatatus and Metaplax longipes were only found in the mudflat, Cleistostoma dilatatum was only found in S. salsa marsh, and Eriocheir sinensis and Helice tientsinensis were widespread in all habitat types (Table 2). The total biomass per trap was the greatest in the mudflat $\left(F_{3,76}=16.11, p<0.001\right)$. However, the Shannon diversity index 
160 value was lowest for the mudflat, and $S$. salsa marsh had the highest biodiversity $\left(F_{3,76}=61.09, p\right.$ $161<0.001)$ (Fig. 2).

\section{Crab species in S. alterniflora marsh}

163 The crabs in S. alterniflora marsh included E. sinensis, Chiromantes haematochir, Chiromantes 164 dehaani, H. tientsinensis, Sesarma plicata, and Uca arcuata (Table 2). With the exception of E. 165 sinensis, all other species belonged to the phytophagous group. E. sinensis and H. tientsinensis 166 were common in all four habitat types, the biomass of E. sinensis in S. alterniflora marsh was 167 only significantly lower than that in $P$. australis marsh $\left(F_{3,76}=60.22, p<0.001\right)$, and the 168 biomass of $H$. tientsinensis in $S$. alterniflora marsh was significantly higher than that in the 169 mudflat but lower than that in $S$. salsa marsh $\left(F_{3,76}=11.28, p<0.001\right)$. C. haematochir and $C$. 170 dehaani were found in all habitat types except the mudflat, and the biomass of these two species 171 in $S$. alterniflora marsh was not significantly different from that in the other habitat types $\left(F_{2,57}=\right.$ $\left.1720.812, p=0.449 ; F_{2,57}=1.36, p=0.265\right)$. S. plicata and $U$. arcuata were only found in $S$. 173 alterniflora marsh and $S$. salsa marsh, the biomass of $S$. plicata in $S$. alterniflora marsh was 174 lower than that in $S$. salsa marsh $\left(F_{1,38}=22.47, p<0.001\right)$, while the biomass of U. arcuata in $S$. alterniflora marsh was greater than that in $S$. salsa marsh $\left(F_{1,38}=39.91, p<0.001\right)$ (Table 2).

\section{Differences in crab community structure according to habitat type} According to the result of the PCA, the first two principal components accounted for a total of $56.9 \%$ of the crab community variation among habitats; PC1 explained $38.3 \%$ of the variation,

180

181

182

183

184

185

186

187

188

189

190

191

192

193

194

195

196

197

198

199 and PC2 explained $18.6 \%$ of the variation (Fig. 3). The points representing the crab communities in $S$. salsa marsh were the most widely scattered and covered the largest area across the coordinate axis, while the points representing those in the mudflat were the most concentrated and covered the least area on the coordinate axis. The area containing the points representing $S$. alterniflora marsh had the largest overlap with that of $S$. salsa marsh but had the lowest overlap with that of the mudflat (Fig. 3). The biomass of S. plicata, H. tientsinensis and C. dilatatum was positively loaded on PC1 and PC2, showing that these species preferred $S$. salsa marsh. The biomass of C. haematochir, C. dehaani and U. arcuata was positively loaded on PC1 but negatively loaded on PC2, showing that these species preferred $S$. alterniflora marsh. The biomass of P. pisum, M. longipes and M. dilatatus was positively loaded on PC2 but negatively loaded on PC1, showing that these species preferred the mudflat. The biomass of E. sinensis was negatively loaded on PC2 but was poorly positively loaded on PC1, showing that this species preferred $P$. australis marsh (Fig. 3).

The ANOSIM revealed significant differences in crab community structure among the habitat types (both globally and for pairwise tests) (global $R=0.849, p<0.001$ ) (Table 3). There were considerably significant differences between the mudflat and the three other habitat types in the pairwise tests (all $R=1.0, p<0.001$ ). The difference between $S$. alterniflora marsh and $S$. salsa marsh was the smallest, but it also reached a significant level $(R=0.537, p<0.001)$ (Table 3).

The SIMPER revealed dissimilarity in the crab community structure ranging from $30.80 \%$ to $80.88 \%$ among habitat types; the dissimilarity between $S$. alterniflora marsh and $S$. salsa 
200

201

202

203

204

205

206

207

208

209

210

211

212

213

214

215

216

217

218

219

220

221

222

223

224

225

226

227

228

229

230

231

232

233

234

235

236

237

238

239

marsh was the lowest (30.8\%) (Table 3). The species that were responsible for the dissimilarity between $S$. alterniflora marsh and $S$. salsa marsh were $C$. dilatatum, C. dehaani and S. plicata (representing $28.46 \%, 13.60 \%$ and $12.33 \%$, respectively). The species that were responsible for the high dissimilarity (79.91\%) between S. alterniflora marsh and the mudflat were P. pisum, $M$. dilatatus and $U$. arcuata (representing $21.86 \%, 17.69 \%$ and $16.93 \%$, respectively). The species responsible for the dissimilarity (79.91\%) between $S$. alterniflora marsh and $P$. australis marsh were $U$. arcuata, E. sinensis and $C$. dehaani (representing $37.85 \%, 14.95 \%$ and $13.15 \%$, respectively) (Table 3 ).

\section{Temporal and spatial variation in individual species}

The multiple bar charts showed that the compositions of the crab communities in each habitat type did not change in different sampling months, but the biomass of individual species changed over time (Fig. 4). The biomass of crabs was most abundant from May to July in almost all habitats. E. sinensis represented the most biomass in May and July, and the biomass in $P$. australis marsh was always significantly higher than that in the three other habitats in all months (Fig. 4A). C. haematochir represented the most biomass in July, and the biomass in $S$.

alterniflora marsh was the highest in July and September but was lower than that in other habitats in April, May and June (Fig. 4B). C. dehaani represented the most biomass in July, and the biomass in S. alterniflora marsh was the highest among all habitats in June and July (Fig. 4C). H. tientsinensis represented the most biomass in June and July, and the biomass in S. alterniflora marsh was the highest in June, while the biomass in S. salsa marsh was the highest in July among all habitats (Fig. 4D). S. plicata represented the most biomass in July, and the biomass in S. alterniflora marsh was always significantly lower than that in $S$. salsa marsh in all months (Fig. 4F). U. arcuata represented the most biomass in July, and the biomass in S. alterniflora marsh was always significantly higher than that in $S$. salsa marsh in all months (Fig. 4H). Of the three endemic species of the mudflat, M. longipes represented the most biomass in May and July, while $P$. pisum and $M$. dilatatus represented the most biomass in June and July (Fig. 4E, G, J). $C$. dilatatum was only found in $S$. salsa marsh and represented the most biomass in September (Fig. 4I).

\section{Discussion}

Although many studies have suggested that $S$. alterniflora invasion has resulted in local biodiversity loss and ecosystem degradation (Li et al. 2009; Yang et al. 2017), a unified conclusion regarding the effects of $S$. alterniflora invasion on macrofaunal species has not been reached (Quan et al. 2016). Recent studies have indicated that the reclamation of soil by $S$. alterniflora invasion can facilitate some taxa, such as fishes and crabs (Feng et al. 2015; Chen \& Ma 2018). Some studies confirm that the leaves of $S$. alterniflora can supply palatable food for $C$. dehaani and S. plicata (Gao et al. 2018; Wang et al. 2008) and that the abundance of $U$. arcuata is positively correlated with $S$. alterniflora cover (Raposa et al. 2018). According to our results, the number of crab species in S. alterniflora marsh was lower than that in S. salsa marsh but greater than that in the mudflat and $P$. australis marsh. The total biomass of crabs in $S$. 
240 alterniflora marsh was lower than that in the mudflat but higher than that in P. australis marsh

241

242

243

244

245

246

247

248

249

250

251

252

253

254

255

256

257

258

259

260

261

262

263

264

265

266

267

268

269

270

271

272

273

274

275

276

277

278

279

and $S$. salsa marsh. The Shannon diversity index value of crabs in $S$. alterniflora marsh was higher than that for the mudflat and $P$. australis marsh and lower than that for $S$. salsa marsh. Therefore, we think that exotic S. alterniflora can offer suitable habitat for some crab species, especially those in the phytophagous group. For example, C. haematochir, C. dehaani, and $U$. arcuata were more abundant in S. alterniflora marsh than in the other habitat types.

Despite the fact that $S$. alterniflora can create suitable environmental conditions that are consistent with the habitat requirements of some crab species (Gao et al. 2018; Wang et al. 2008), invasion may reduce the ecological niches of habitat-specific crabs. S. alterniflora is more competitive than native plants, especially in the mudflat and $S$. salsa marsh, and rapidly replaces these two habitat types (Zuo et al. 2012). According to our results, the crab biomass in the mudflat was the largest among all habitat types (Fig. 2); for example, M. longipes, P. pisum and M. dilatatus only preferred the mudflat habitat (Table 2; Fig. 4). These species prefer to forage in low-altitude flooded habitats, but alien S. alterniflora accelerated sediment deposition and increased the elevation in invaded areas (Chen 2014). The Shannon diversity index value for crabs was highest in $S$. salsa marsh (Fig. 2), and C. dilatatum was only found in $S$. salsa marsh (Table 2; Fig. 4), perhaps because $S$. alterniflora marsh does not provide the preferred food of this species. The loss of suitable habitat may cause the dramatic decline of populations of these crab species. The crab community structure in S. alterniflora marsh was significantly different from that in the mudflat according to the results of the PCA, ANOSIM and SIMPER (Fig. 3; Table 3), which means that even though $S$. alterniflora marsh hosts a considerable number of crabs, this habitat containing exotic vegetation may not perform the same ecological function as the mudflat.

Exotic plant invasions may have a cascading effect on higher trophic levels and ultimately impair overall biodiversity (Brusati \& Grosholz 2009). The effects of S. alterniflora invasion on the distribution of crabs may have a major impact on other related biological groups in the food web (Gittman \& Keller 2013). The wetlands along the Yellow Sea coast of China are a vital feeding habitat for shorebirds in the East Asian-Australasian Flyway (Melville et al. 2016). During the annual migration period, a large number of shorebirds rely on the predation of benthos to gain energy to complete migration (Hou et al. 2013). Many studies have confirmed that the highly dense structure of $S$. alterniflora is not suitable for medium and large shorebirds (Delach 2006), and most native birds avoid using S. alterniflora marsh (Ma et al. 2011).

Therefore, although $S$. alterniflora marsh is rich in crab resources according to our results, it seems to offer little help to migratory birds. Many plovers and dunlins prefer to forage on the mudflat (Buchanan 2003; Melville et al. 2016), and some large, rare birds prey on crabs in $S$. salsa marsh (Hemmi et al. 2006), such as Grus japonensis foraging on H. tientsinensis (Li et al. 2014). S. alterniflora invasion may seriously damage the feeding habitat of these waterfowl and cause a decrease in some bird populations because of the inadequate food supply. In contrast, the adverse foraging environment of $S$. alterniflora marsh may provide crabs with a refuge from birds (Nomann \& Pennings 1998; Sueiro et al. 2012), resulting in the higher biomass and

Peer) reviewing PDF | (2018:12:33401:1:1:NEW 27 Feb 2019) 
280

281

282

283

284

285

286

287

288

289

290

291

292

293

294

295

296

297

298

299

300

301

302

303

304

305

306

307

308

309

310

311

312

313

314

315

316

317

318

319

320

321

322

diversity of crabs.

\section{Conclusions}

This study examined the distribution of crab communities along a habitat gradient from the shoreline to inland areas on the Yellow Sea coast in China, where the invasion of S. alterniflora has seriously encroached on the mudflat and native vegetation. Our results reveal that the crab community in S. alterniflora marsh is slightly different from that associated with the local vegetation but shows a large difference from that in the mudflat. This study indicates that $S$. alterniflora marsh can offer suitable habitat for some crab species, while some habitat-specific crab species reject this new habitat. The effects of the distribution of crabs after $S$. alterniflora invasion on the regional ecosystem will need further study in the future.

\section{Acknowledgements}

We thank Bin Liu and patrols at Yancheng National Natural Reserve for assistance and support in the field sampling.

\section{References}

Bray JR and Curtis JT. 1957. An ordination of the upland forest communities of southern Wisconsin. Ecological Monographs 27:325-349. DOI 10.2307/1942268

Brusati ED, and Grosholz ED. 2006. Native and introduced ecosystem engineers produce contrasting effects on estuarine infaunal communities. Biological Invasions 8:683-695. DOI 10.1007/s10530-005-2889-y

Brusati ED, and Grosholz ED. 2009. Does invasion of hybrid cordgrass change estuarine food webs? Biological Invasions 11:917-926. DOI 10.1007/s10530-008-9304-4

Buchanan JB. 2003. Spartina invasion of Pacific coast estuaries in the United States: Implications for shorebird conservation. Wader Study Group Bulletin 100:44-47.

Butchart SHM, Walpole M, Collen B, van Strien A, Scharlemann JPW, Almond REA, Baillie JEM, Bomhard B, Brown C, Bruno J, Carpenter KE, Carr GM, Chanson J, Chenery AM, Csirke J, Davidson NC, Dentener F, Foster M, Galli A, Galloway JN, Genovesi P, Gregory RD, Hockings M, Kapos V, Lamarque JF, Leverington F, Loh J, McGeoch MA, McRae L, Minasyan A, Morcillo MH, Oldfield TEE, Pauly D, Quader S, Revenga C, Sauer JR, Skolnik B, Spear D, Stanwell-Smith D, Stuart SN, Symes A, Tierney M, Tyrrell TD, Vie JC, and Watson R. 2010. Global Biodiversity: Indicators of Recent Declines. Science 328:1164-1168. DOI 10.1126/science.1187512

Chen J. 2014. Evolution characteristic and reclamation potentiality of the muddy coast in Jiangsu Province, China. Applied Mechanics and Materials 577:1185-1188. DOI 10.4028/www.scientific.net/AMM.577.1185

Chen Q, and Ma K. 2018. Determining Whether Exotic Cordgrass (Spartina alterniflora) Attracts Carnivorous Macrobenthic Fauna within a Zhanjiang (China) Mangrove Ecosystem. Journal of Coastal Research 34:534-543. DOI 10.2112/jcoastres-d-1600223.1

Clarke KR and Warrick RM. 1994. Similarity-based testing for community pattern: the two-way layout with no replication. Marine Biology 118:167-176. DOI 10.1007/BF00699231 
323

324

325

326

327

328

329

330

331

332

333

334

335

336

337

338

339

340

341

342

343

344

345

346

347

348

349

350

351

352

353

354

355

356

357

358

359

360

361

362

363

364

365

366

367

368
Clarke KR and Warrick RM. 2001. Change in marine communities: an approach to statistical analysis and interpretation. 2nd Edition. Plymouth, UK: PRIMER-E.

Cui BS, He Q, and An Y. 2011. Spartina alterniflora invasions and effects on crab communities in a western Pacific estuary. Ecological Engineering 37:1920-1924. DOI 10.1016/j.ecoleng.2011.06.021

Delach A. 2006. Invasive Species in the Northwestern United States: Threats to Wildlife, and Defenders of Wildlife's Recommendation for Prevention Policies. Northwestern Naturalist 87:43-55. DOI 10.1898/1051-1733(2006)87[43:ISITNU]2.0.CO;2

Feng JX, Huang Q, Qi F, Guo JM, and Lin GH. 2015. Utilization of exotic Spartina alterniflora by fish community in the mangrove ecosystem of Zhangjiang Estuary: evidence from stable isotope analyses. Biological Invasions 17:2113-2121. DOI 10.1007/s10530-0150864-9

Gao J, Bai F, Yang Y, Gao S, Liu Z, and Li J. 2012. Influence of Spartina Colonization on the Supply and Accumulation of Organic Carbon in Tidal Salt Marshes of Northern Jiangsu Province, China. Journal of Coastal Research 28:486-498. DOI 10.2112/jcoastres-d-1100062.1

Gao X, Wang M, Wu H, Wang W, and Tu Z. 2018. Effects of Spartina alterniflora Invasion on the Diet of Mangrove Crabs (Parasesarma plicata) in the Zhangjiang Estuary, China. Journal of Coastal Research 34:106-113. DOI 10.2112/jcoastres-d-17-00002.1

Genovesi P, Carboneras C, Vilà M, and Walton P. 2015. EU adopts innovative legislation on invasive species: a step towards a global response to biological invasions? Biological Invasions 17:1307-1311. DOI 10.1007/s10530-014-0817-8

Gittman RK, and Keller DA. 2013. Fiddler crabs facilitate Spartina alterniflora growth, mitigating periwinkle overgrazing of marsh habitat. Ecology 94:2709-2718. DOI 10.1890/13-0152.1

Hemmi JM, Marshall J, Pix W, Vorobyev M, and Zeil J. 2006. The variable colours of the fiddler crab Uca vomeris and their relation to background and predation. Journal of Experimental Biology 209:4140-4153. DOI 10.1242/jeb.02483

Hou SL, Yu XY, and Lu CH. 2013. Relationships between shorebirds and macrobenthos in Sheyang Estuary of Yancheng Reserve, East China in spring. Chinese Journal of Ecology 32 2735-2743. DOI 10.13292/j.1000-4890.2013.0312

Jiang ZG, and Ding YH. 2011. Milu and biodiversity in Dafeng. Beijing: Beijing Forestry Press.

Levin LA, and Talley TS. 2002. Influences of vegetation and abiotic environmental factors on salt marsh invertebrates. In: Weinstein MP, and Kreeger DA, eds. Concepts and controversies in tidal marsh ecology. Dordrecht: Springer, 661-707.

Li B, Liao CH, Zhang XD, Chen HL, Wang Q, Chen ZY, Gan XJ, Wu JH, Zhao B, Ma ZJ, Cheng XL, Jiang LF, and Chen JK. 2009. Spartina alterniflora invasions in the Yangtze River estuary, China: An overview of current status and ecosystem effects. Ecological Engineering 35:511-520. DOI 10.1016/j.ecoleng.2008.05.013

Li DL, Ding YQ, Yuan Y, Lloyd H, and Zhang ZW. 2014. Female tidal mudflat crabs represent a critical food resource for migratory Red-crowned Cranes in the Yellow River Delta, China. Bird Conservation International 24:416-428. DOI 10.1017/s0959270913000555

Liu J, Chen H, Kowarik I, Zhang Y, and Wang R. 2012. Plant invasions in China: an emerging hot topic in invasion science. Neobiota 15:27-51. DOI 10.3897/neobiota.15.3751

Ma ZJ, Gan XJ, Cai YT, Chen JK, and Li B. 2011. Effects of exotic Spartina alterniflora on the habitat patch associations of breeding saltmarsh birds at Chongming Dongtan in the

PeerJ reviewing PDF | (2018:12:33401:1:1:NEW 27 Feb 2019) 
369

370

371

372

373

374

375

376

377

378

379

380

381

382

383

384

385

386

387

388

389

390

391

392

393

394

395

396

397

398

399

400

401

402

403

404

405

406

407

408

409

410

411

412

413

414

Yangtze River estuary, China. Biological Invasions 13:1673-1686. DOI 10.1007/s10530010-9924-3

Melville DS, Chen Y, and Ma ZJ. 2016. Shorebirds along the Yellow Sea coast of China face an uncertain future - a review of threats. Emu 116:100-110. DOI 10.1071/mu15045

Navarro-Barranco C, Manuel Tierno-de-Figueroa J, Manuel Guerra-Garcia J, Sanchez-Tocino L, and Carlos Garcia-Gomez J. 2013. Feeding habits of amphipods (Crustacea: Malacostraca) from shallow soft bottom communities: Comparison between marine caves and open habitats. Journal of Sea Research 78:1-7. DOI 10.1016/j.seares.2012.12.011

Nishijima S, Takimoto G, and Miyashita T. 2016. Autochthonous or allochthonous resources determine the characteristic population dynamics of ecosystem engineers and their impacts. Theoretical Ecology 9:117-127. DOI 10.1007/s12080-015-0274-8

Nomann BE, and Pennings SC. 1998. Fiddler crab-vegetation interactions in hypersaline habitats. Journal of Experimental Marine Biology and Ecology 225:53-68. DOI 10.1016/S0022-0981(97)00209-8

Quan WM, Zhang H, Wu ZL, Jin SF, Tang FH, and Dong JB. 2016. Does invasion of Spartina alterniflora alter microhabitats and benthic communities of salt marshes in Yangtze River estuary? Ecological Engineering 88:153-164. DOI 10.1016/j.ecoleng.2015.12.026

Raposa KB, McKinney RA, Wigand C, Hollister JW, Lovall C, Szura K, Gurak JA, McNamee J, Raithel C, and Watson EB. 2018. Top-down and bottom-up controls on southern New England salt marsh crab populations. Peerj 6:25. DOI 10.7717/peerj.4876

Reise K. 2002. Sediment mediated species interactions in coastal waters. Journal of Sea Research 48:127-141. DOI 10.1016/S1385-1101(02)00150-8.

Sheehan MR, and Ellison JC. 2014. Intertidal morphology change following Spartina anglica introduction, Tamar Estuary, Tasmania. Estuarine Coastal and Shelf Science 149:24-37. DOI 10.1016/j.ecss.2014.07.006

Sueiro MC, Bortolus A, and Schwindt E. 2012. The role of the physical structure of Spartina densiflora Brong. in structuring macroinvertebrate assemblages. Aquatic Ecology 46:2536. DOI 10.1007/s10452-011-9379-3

Wang JQ, Bertness MD, Li B, Chen JK, and Lu WG. 2015. Plant effects on burrowing crab morphology in a Chinese salt marsh: Native vs. exotic plants. Ecological Engineering 74:376-384. DOI 10.1016/j.ecoleng.2014.11.019

Wang JQ, Zhang XD, Nie M, Fu CZ, Chen JK, and Li B. 2008. Exotic Spartina alterniflora provides compatible habitats for native estuarine crab Sesarma dehaani in the Yangtze River estuary. Ecological Engineering 34:57-64. DOI 10.1016/j.ecoleng.2008.05.015

Wickham H. 2016. ggplot2: Elegant Graphics for Data Analysis. New York: Springer-Verlag. Yang W, Qiao YJ, Li N, Zhao H, Yang R, Leng X, Cheng XL, and An SQ. 2017. Seawall construction alters soil carbon and nitrogen dynamics and soil microbial biomass in an invasive Spartina alterniflora salt marsh in eastern China. Applied Soil Ecology 110:111. DOI 10.1016/j.apsoil.2016.11.007

Zhang SY, He XB, Wang JJ, Lin HS, Huang YQ, Lin JH, Mou JF, Liu K and Zheng CX. 2017. Characteristics of the benthic crustacean community structures and functional groups around the Luoyang Estuary in Fujian. Acta Ecologica Sinica 37:5961-5972. DOI: 10.5846/stxb201607011353

Zuo P, Zhao SH, Liu CA, Wang CH, and Liang YB. 2012. Distribution of Spartina spp. along China's coast. Ecological Engineering 40:160-166. DOI 10.1016/j.ecoleng.2011.12.014 


\section{Table 1 (on next page)}

Plant characteristics in three habitat types at Yancheng National Nature Reserve

Shown are the mean \pm SE. Different letters $(a-c)$ indicate significant differences between habitat types $(p<0.05)$. Habitat types: Sp, S. alterniflora marsh; Su, S. glauca marsh; Ph, $P$. australis marsh. 
1

\begin{tabular}{lccccccc}
\hline & \multicolumn{5}{c}{ Habitat type } & & \\
Plant characteristic & $\mathrm{Sp}$ & $\mathrm{Su}$ & $\mathrm{Ph}$ & & $p$ \\
\cline { 2 - 6 } & $134.56 \pm 3.25 \mathrm{~b}$ & $31.94 \pm 0.81 \mathrm{c}$ & $181.51 \pm 3.25 \mathrm{a}$ & 2,297 & 805.4 & $<0.001$ \\
\hline Height $(\mathrm{cm}, \mathrm{n}=100)$ & $152.30 \pm 8.60 \mathrm{a}$ & $19.3 \pm 1.95 \mathrm{c}$ & $116.90 \pm 7.83 \mathrm{~b}$ & 2,27 & 102.4 & $<0.001$ \\
Density $\left(\mathrm{stem} \cdot \mathrm{m}^{-2}, \mathrm{n}=10\right)$ & & & & & & \\
\hline
\end{tabular}




\section{Table 2 (on next page)}

Densityof crab species in four habitat types at Yancheng National Nature Reserve

Shown are the mean \pm SE. Different letters $(a-c)$ indicate significant differences between habitats $(p<0.05)$. "-" Indicates that no sample obtained. Habitat types: Mu, Mudflat; Sp, S. alterniflora marsh; Su, S. salsa marsh; Ph, P. australis marsh. Functional feeding groups: C, Camivorous group; P, Phytophagous group; O, Omnivorous group. 
1

\begin{tabular}{|c|c|c|c|c|c|c|c|}
\hline \multirow{2}{*}{ Crab species (num/per quadrat, $n=20$ ) } & \multicolumn{4}{|c|}{ Habitat type } & \multirow{2}{*}{$d f$} & \multirow{2}{*}{$F$} & \multirow{2}{*}{$p$} \\
\hline & $\mathrm{Mu}$ & $\mathrm{Sp}$ & $\mathrm{Su}$ & $\mathrm{Ph}$ & & & \\
\hline 1. Eriocheir sinensis $(\mathrm{C})$ & $1.95 \pm 0.37 b$ & $3.00 \pm 0.46 b$ & $2.05 \pm 0.31 b$ & $17.10 \pm 1.79 \mathrm{a}$ & 3,76 & 60.22 & $<0.001$ \\
\hline 2. Chiromantes haematochir $(\mathrm{P})$ & - & $7.10 \pm 2.02$ & $8.60 \pm 1.31$ & $6.00 \pm 0.72$ & 2,57 & 0.812 & 0.449 \\
\hline 3. Chiromantes dehaani (P) & - & $10.60 \pm 2.49$ & $6.40 \pm 1.58$ & $9.20 \pm 1.18$ & 2,57 & 1.36 & 0.265 \\
\hline 4. Helice tientsinensis $(\mathrm{P})$ & $2.05 \pm 0.37 \mathrm{c}$ & $6.75 \pm 1.36 b$ & $11.65 \pm 1.68 \mathrm{a}$ & $6.50 \pm 0.80 \mathrm{bc}$ & 3,76 & 11.28 & $<0.001$ \\
\hline 5. Metaplax longipes $(\mathrm{P})$ & $1.55 \pm 0.32$ & - & - & - & - & - & - \\
\hline 6. Sesarma plicata $(\mathrm{O})$ & - & $0.95 \pm 0.22 b$ & $3.5 \pm 0.49 \mathrm{a}$ & - & 1,38 & 22.47 & $<0.001$ \\
\hline 7. Philyra pisum $(\mathrm{O})$ & $56.85 \pm 17.81$ & - & - & - & - & - & - \\
\hline 8. Uca arcuata $(\mathrm{P})$ & - & $19.65 \pm 1.95 \mathrm{a}$ & $5.70 \pm 1.03 b$ & - & 1,38 & 39.91 & $<0.001$ \\
\hline 9. Cleistostoma dilatatum $(\mathrm{P})$ & - & - & $7.00 \pm 0.94$ & - & - & - & - \\
\hline 10. Macrophthalmus dilatatus $(\mathrm{P})$ & $30.50 \pm 7.26$ & - & - & - & - & - & - \\
\hline
\end{tabular}

2 


\section{Table 3 (on next page)}

Results of ANOSIM and SIMPER for community structure by habitat type

Global $R=0.85 ; p=0.001 ;$ Permutation $N=999$. Habitat types: Mu, Mudflat; Sp, $S$. alterniflora marsh; Su, S. salsa marsh; Ph, P. australis marsh. 


\begin{tabular}{|c|c|c|c|c|c|c|c|c|c|}
\hline \multirow{2}{*}{ Group } & \multicolumn{2}{|c|}{ ANOSIM } & \multicolumn{7}{|c|}{ SIMPER } \\
\hline & $R$ & $p$ & $\begin{array}{c}\text { Dissimilarity } \\
(\%)\end{array}$ & $\begin{array}{c}\text { Discriminating } \\
\text { Species1 }\end{array}$ & $\begin{array}{c}\text { Contribution } \\
(\%)\end{array}$ & $\begin{array}{c}\text { Discriminating } \\
\text { Species2 }\end{array}$ & $\begin{array}{c}\text { Contribution } \\
(\%)\end{array}$ & $\begin{array}{c}\text { Discriminating } \\
\text { Species3 }\end{array}$ & $\begin{array}{c}\text { Contribution } \\
(\%)\end{array}$ \\
\hline $\mathrm{Mu}-\mathrm{Sp}$ & 1 & 0.001 & 79.91 & P. pisum & 21.86 & M. dilatatus & 17.69 & U. arcuata & 16.93 \\
\hline $\mathrm{Mu}-\mathrm{Su}$ & 1 & 0.001 & 80.88 & P. pisum & 18.78 & M. dilatatus & 15.14 & C. haematochir & 11.12 \\
\hline $\mathrm{Mu}-\mathrm{Ph}$ & 1 & 0.001 & 74.56 & $P$. pisum & 24.97 & M. dilatatus & 20.22 & C. dehaani & 16.03 \\
\hline $\mathrm{Sp}-\mathrm{Su}$ & 0.55 & 0.001 & 30.80 & C. dilatatum & 28.46 & C. dehaani & 13.60 & S. plicata & 13.23 \\
\hline $\mathrm{Sp}-\mathrm{Ph}$ & 0.75 & 0.001 & 37.57 & U. arcuata & 37.85 & E. sinensis & 14.95 & C. dehaani & 13.15 \\
\hline $\mathrm{Su}-\mathrm{Ph}$ & 0.99 & 0.001 & 37.86 & C. dilatatum & 24.56 & U. arcuata & 21.81 & S. plicata & 19.82 \\
\hline
\end{tabular}




\section{Figure 1}

Maps of habitat types and sample sites at YanchengNational Nature Reserve

Habitat types: Mu, mudflat; Sp, S. alterniflora marsh; Su, S. salsa marsh; Ph, P. australis marsh. Map data @ 2017 Google
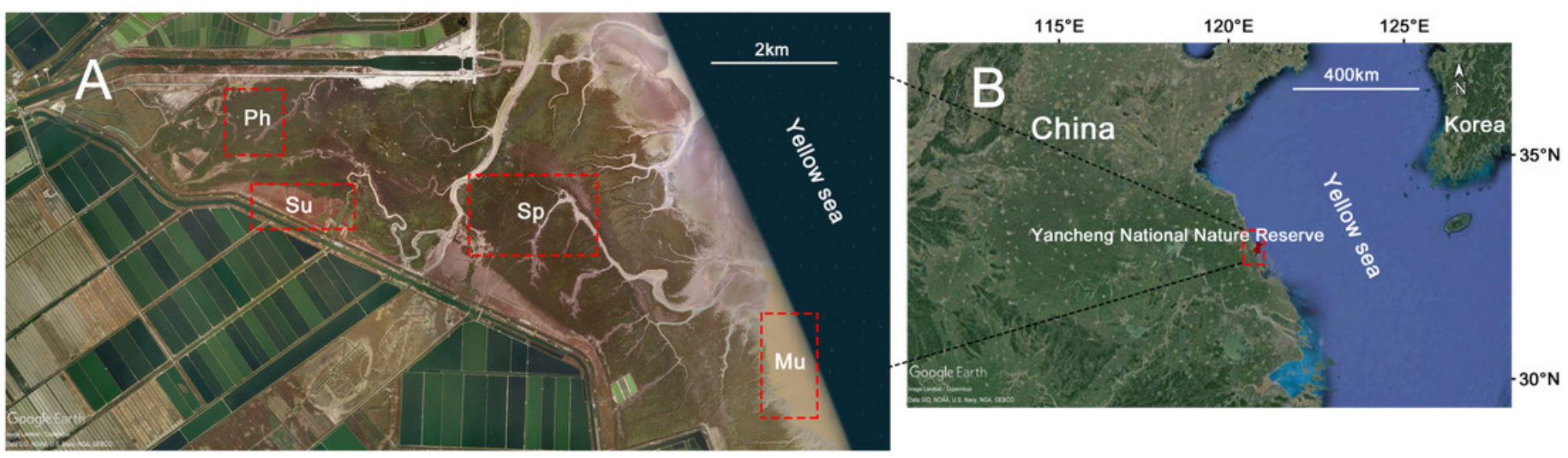
Figure 2 (on next page)

Differences in crab biomass and Shannon diversity index among four habitat types at Yancheng National Nature Reserve

Different letters (a-c) indicate significant differences between habitat types $(p<0.05)$. Habitat types: Mu, mudflat; Sp, S. alterniflora marsh; Su, S. salsa marsh; Ph, P. australis marsh. 

Figure 3 (on next page)

The mosaic plot of crab community in different months and habitat types at Yancheng National Nature Reserve

Habitat types: Mu, mudflat; Sp, S. alterniflora marsh; Su, S. salsa marsh; Ph, P. australis marsh. 
Figure 4 (on next page)

Plots of spatiotemporal variation of individual species biomass

Habitat types: Mu, mudflat; Sp, S. alterniflora marsh; Su, S. salsa marsh; Ph, P. australis marsh. 

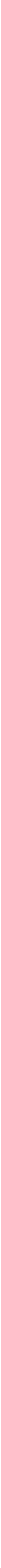